\title{
Incidental Enterobius Vermicularis infestation in surgically removed appendices with a clinical diagnosis of acute appendicitis: A retrospective analysis
}

\author{
Upadhyaya $\mathrm{P}^{1}$, Sinha $\mathrm{AK}^{1}$, Agarwal $\mathrm{M}^{1}$, Paudyal $\mathrm{P}^{1}$, Shrestha $\mathrm{A}^{1}$ \\ ${ }^{I}$ Department of Pathology, B.P.Koirala Instittue of Health Sciences, Dhahran. Nepal
}

\section{Keywords: \\ Appendix; Acute appendicitis; Enterobius; Oxyuriasis;}

\begin{abstract}
Background: Appendiceal parasites can cause symptoms of appendicitis. Although the symptomatology imitates acute appendicitis clinically, the true nature of disease is diagnosed through histological examination. The aim of this study is to therefore determine the prevalence of E. Vermicularis in appendicectomy specimens to relate this to acute inflammation histologically.
\end{abstract}

Materials and methods: Histological data on all appendectomy specimens with a clinical diagnosis of acute appendicitis were retrieved from the archives of department of pathology, B.P.K.I.H.S, over the period of five years (January 2004- December 2008) and was analyzed retrospectively.

Results: There were a total of 1528 patients. M:F ratio being 1.2:1. Inflamed appendix constituted for $94.24 \%$ of all cases. There were a total of $\operatorname{six}(0.39 \%)$ appendicectomy specimens which showed presence of oxyuriasis appendix. Though all patients with oxyuriasis presented with appendicial colic only one out of the six cases of oxyuriasis showed histologic evidence of inflammation.

Conclusion: We conclude that enterobius does not frequently cause inflammation of appendix though it may clinically mimic acute appendicitis. Since it represents a disease curable without necessitating surgery, symptomatology awareness is stressed upon.

\section{INTRODUCTION}

Appendicitis is the most common surgical cause of acute abdominal pain, affecting $7 \%$ of humans during their lifetimes. ${ }^{1}$ The life time risk as shown by a study of acute appendicitis for men and women is $8.6 \%$ and $6.7 \%$, respectively, however, the lifetime risk of having

\section{Correspondence:}

Dr. Paricha Upadhyaya, $M D$

Department of Pathology

B.P.Koirala Instittue of Health Sciences, Dhahran. Nepal

Email:paricha7@yahoo.com an appendectomy is $12 \%$ for men and $25 \%$ for women. ${ }^{2}$ Approximately $15 \%$ of appendicectomy resulted in removal of normal appendix as evidenced by a study. ${ }^{3}$

However the negative appendicectomy rate reported in the literature varies; typical figures are between $7 \%$ and $20 \%$ in men and $20 \%$ and $45 \%$ in women. ${ }^{4}$ These are high figures for a common disease at the threshold of the $21^{\text {st }}$ century and they persist despite many attempts to refine the preoperative diagnosis. Studies carried out around a decade back have quoted that the negative appendicectomy rate has remained 
largely unchanged over the last 70 years. ${ }^{5}$

One such cause of negative appendicectomy could be infestation of the appendix by Enterobius vermicularis, commonly known as pinworm or threadworm, responsible for a widespread parasite infection estimation to affect up to 209 million people worldwide. ${ }^{6}$ The possible role of the parasite in causing acute appendicitis has been a matter of great dispute and has been discussed for almost more than 100 years. $^{7}$

The presence of the parasite in the appendix was first reported by Fabrius in $1634 .{ }^{8}$ Pinworm measures approximately $10 \mathrm{~mm}$ in length and lives with their heads embedded in the right hemicolon and adjacent bowel. The most common mode of transmission is through fecal-oral route and eggs of the pinworm may remain viable for two to three weeks on clothing and bedding, facilitating easy spread among family members and groups of children. Usually the patients are asymptomatic. The most common clinical presentation is prutitus in perianal region, but infestation may also present with ileocolitis, enterocutaneous fistula, urinary tract infestion, mesenteric abscess, salpingitis and appendicitis. The presence of E. Vermicularis is associated with chronic inflammatory infiltrate and eosinophilia. ${ }^{6}$

In spite of all these findings there still exists a controversy regarding the causal relationship between the parasite and acute appendicitis. This study is taken up with an attempt to see whether appendecial colic associated with enterobius is associated with microscopic evidence of acute appendicitis. The aim of this study was to find out the prevalence of Enterobius infestation in clinically diagnosed cases of acute appendicitis and to assess the histologic picture of appendix infested with Enterobius Vermicularis.

\section{MATERIALS AND METHODS}

This was a retrospective study which included the entire appendectomy specimen collected from January 2004 to December 2008. Permission was taken from institutional review committee. Histological data on all appendectomy specimens with a clinical diagnosis of acute appendicitis were retrieved from the archives of department of pathology, B.P.K.I.H.S. The cases were also retrospectively reviewed for the presence of Enterobius Vermicularis and its association with inflammation.

\section{RESULTS}

There were total numbers of 1528 patients in our study; out of which 855 were males and 673 were females. The male to female ratio is $1.2: 1$. Table 1 shows the distribution of males and females according to the age group. The highest frequency was in the second decade (33.51\%) which was closely followed by patients in the third decade $(28.93 \%)$. Therefore, it can be concluded from the age pattern of this

\begin{tabular}{|c|c|c|c|}
\hline \multirow{2}{*}{$\begin{array}{l}\text { Age groups } \\
\text { (Year) }\end{array}$} & \multicolumn{2}{|c|}{ No of cases } & \multirow{2}{*}{ Total } \\
\hline & Male & Female & \\
\hline $1-10$ & 78 & 64 & $142(9.29)$ \\
\hline$>50$ & 79 & 51 & $130(8.51)$ \\
\hline $11-20$ & 287 & 225 & $512(33.51)$ \\
\hline $21-30$ & 256 & 186 & $442(28.93)$ \\
\hline $31-40$ & 103 & 123 & $226(14.79)$ \\
\hline $41-50$ & 52 & 24 & $76(4.97)$ \\
\hline TOTAL & 855 & 673 & $1528(100.0)$ \\
\hline
\end{tabular}

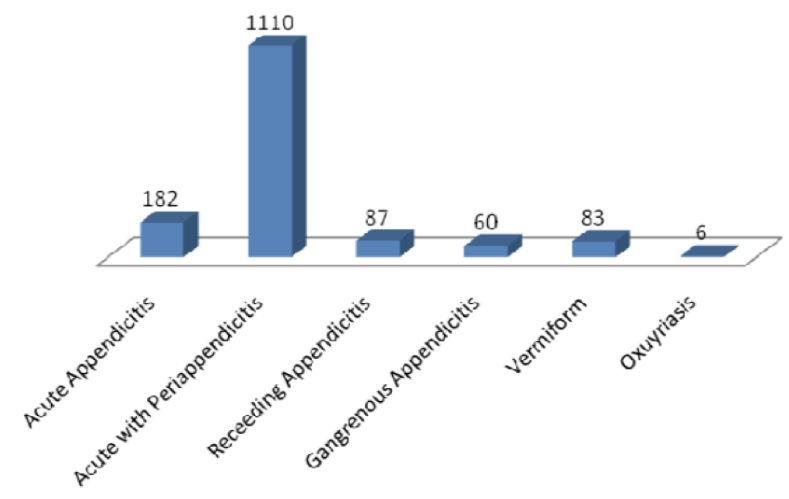

Figure 1: Histologial variations in appendix

study that majority patient fall in the second to third decade.

Figure 1 shows the histologic breakdown of the cases. Total number inflamed appendices were 1445. The degree of inflammation varied from acute appendicitis, in which inflammation is limited to the appendix, to periappendicitis and even with gangrenous change. There were also cases which showed resolving inflammation and that were categorized as receding appendicitis Therefore inflamed appendix constituted for $94.24 \%$ of all cases and $5.75 \%$ of cases did not show any signs of inflammation. Five out of six cases of oxyuriasis appendix also did not show any signs of inflammation.

Appendix specimens with presence of enterobius vermicularis (oxyuriasis) were grouped separately where there were a total of six cases. Therefore it constituted around $0.39 \%$ of all appendicectomy cases.

These six specimens which showed presence of enterobius vermicularis were analysed retrospectively for available clinical and laboratory details. The age ranged from 4 years to 32 years. The dominant histologic picture was that of normal appendix $(83.33 \%)$ with only one case showing acute appendicitis with periappendicitis. The microscopic picture 
of the patient having appendicitis with periappendicitis showed mucosal ulceration with transmural inflammation and presence of the parasite in the lumen of appendix.

\section{DISCUSSION}

Appendectomy is one of the most frequently performed surgical procedures in the world as acute appendicitis is the most common surgical emergency that may be due to the obstruction of the appendiceal lumen and seems to be essential for developing an appendiceal infection.9 Enterobius vermicularis is a cosmopolitan parasite of humans residing in the lumen of the ceacum and appendix, and the most common parasite helminths of humans in temperate, developed countries. ${ }^{10}$ The spectrum of inflammatory changes in appendicitis varies however it has been seen in studies that even normal appendices are surgically removed contributing to a negative appendicectomy rate of 20 to $40 \% .{ }^{11}$ The negative appendicectomy rate in our study was $5.75 \%$.

The relationship of E.vermicularis in causing appendicitis and its presence in appendicectomy specimens has been a subject of study for many years. In our study of 1528 appendicectomy specimens, enterobius was found in 6 cases; contributing to $0.39 \%$ of total appendicectomies. Similarly studies done in the past have shown presence of Enterobius vermicularis in $1.5 \%{ }^{12}, 2.1 \%^{13}, 2.9 \%^{7}, 3.4 \%^{14}$. $2.8 \% .^{15}$ There also has been an attempt in the past to see the relationship of enterobius with inflammatory changes in appendix. Dhalstrom et al in their study of 1867 appendicectomy specimens found that $63 \%$ of patients with enterobius vermicularis had no histologic picture of appendicitis. However $98 \%$ presented clinically with acute appendicitis. ${ }^{14}$ Similarly there are other studies in which only $0.5 \%$ showed appendicitis while $7 \%$ showed a vermiform appendix. ${ }^{16}$ Our study also showed an almost similar result of $100 \%$ of patients presenting with appendicial colic but only one out of 6 cases with enterobius in the lumen of appendix actually revealed features of acute inflammation. Therefore, our study shows that Enterobius frequently does not cause inflammation of appendix (83.3\%). Regarding the clinical and laboratory parameters of these patients it has been observed that all patients had clinical features of acute appendicitis, therefore an appendicectomy at that point could have been clinically justified. Majority of the studies done in the past have said that the presence of pinworm in the appendix can produce symptoms of acute appendicitis which is also referred to as pseudoappendicitis or appendecial colic. ${ }^{7,10,13,16}$

\section{CONCLUSION}

Parasitosis is a public health problem and this study describes that appendices infested with parasites particularly E. vermicularis represent a curable disease which does not necessitate surgery. Its management is totally different from that of classical appendicitis which requires surgery. This condition can be controlled by antihelminthic treatment, yet very unfortunately patients undergo an appendicectomy. An awareness and a high index of suspicion is required since these patients generally have multiple previous visits to the hospital with abdominal discomfort before an acute abdomen that requires surgery. Careful examination and sympatomatology awareness, such as pruritus ani or eosinophilia in the blood examination especially in younger age group should aware surgeon of possible cause of abdominal colic. However, it is a must that these patients should receive an antihelminthic therapy even after appendicectomy as appendicectomy only eliminates the consequence of the disease but not its cause.

\section{REFERENCES}

1. 1. Peltokallio P, Tykkä H. Evolution of the age distribution and mortality of acute appendicitis. Arch Surg 1981;116:153-6. Crossref

2. Flum DR, Koepsell T. The clinical and economic correlates of misdiagnosed appendicitis: nationwide analysis. Arch Surg 2002;137:799-804. Crossref

3. Shelton T, McKinlay R, Schwartz RW. Acute appendicitis: current diagnosis and treatment. Curr Surg. 2003;60:502-5. Crossref

4. Carr NJ. The pathology of acute appendicitis. Ann Diagn Pathol. 2000;4:46-58. Crossref

5. Hale D a, Molloy M, Pearl RH, Schutt DC, Jaques DP. Appendectomy: a contemporary appraisal. Annals of surgery. 1997. pp 252-61. Crossref

6. Panidis S, Paramythiotis D, Panagiotou D, et al. Acute appendicitis secondary to Enterobius vermicularis infection in a middle aged man: a case report. J Med Case Rep. 2011;5:559. Crossref

7. Ramezani MA, Dehghani MR. Relationship between Enterobius vermicularis and the incidence of acute appendicitis. Southeast Asian J Trop Med Public Health. 2007;38:20-3. Crossref

8. Fry GF, Moore JG. Enterobius vermicularis: 10,000-year-old human infection. Science 1969;166:1620. Crossref

9. Akbulut S, Tas M, Sogutcu N, et al. Unusual histopathological findings in appendectomy specimens : A retrospective analysis and literature review. World J Gastroenterol. 2011;17:1961-70. Crossref

10. Waseem M, Simha S. Appendicitis: a rare cause. J Emerg Med. 2011;41:e9-11. Crossref

11. Lewis FR, Holcroft JW, Boey J, Dunphy E. Appendicitis. A critical review of diagnosis and treatment in 1,000 cases. Arch Surg. 1975;110:677-84. Crossref

12. Williams DJ, Dixon MF. Sex, Enterobius vermicularis and the appendix. Br J Surg. 1988;75:1225-6. Crossref

13. Aydin O. Incidental parasitic infestations in surgically removed appendices: a retrospective analysis. Diagn Pathol. 2007;2:16. Crossref

14. Dahlstrom JE, Macarthur EB. Enterobius vermicularis: a possible cause of symptoms resembling appendicitis. Aust N Z J Surg. 1994;64:692-4. Crossref

15. Zakaria OM, Zakaria HM, Daoud MY. Parasitic infestation in pediatric and adolescent appendicitis: a local experience. Oman Med J. 2013;28:92-6. Crossref

16. Budd JS, Armstrong C. Role of Enterobius vermicularis in the aetiology of appendicitis. Br J Surg. 1987;74:748-9. Crossref 